\title{
Method of Quantitative Evaluation of Kimberlite Pipes' Productivity
}

Vouiko, V.I.

YaGEER\&D CNIGRI, ALROSA Co. Ltd. Chernyshevsky Sh. 7, Mirny, 678170, Sakha (Yakutia), Russia.

Among the existing methods of evaluation of kimberlites' diamondiferousness the leading part belongs to mineralogical ones as the most effective. They make it possible to refer garnets with certainty to various deep-seated mineral associations including the ones with diamond. There are known, suggested in different time by Sobolev N.V. [1974], Matsouk S.S., et al [1985] and Griffin W.L., et al [1993] mineralogical methods of diamondiferousness' evaluation. We made an attempt to carry out comparative analysis of their efficiency and on the basis of it to reveal the dependence between the grade of garnets of diamond-pyrope deep-seated facies and productivity of kimberlite bodies. The data about grade of garnets, ilmenites and diamonds in 594 crushed samples from 32 kimberlite pipes with different level of diamondiferous property of Yakutian province served as the material for analysis. Several tens of thousands of garnets were investigated in these samples with the help of X-ray spectrum analysis and optical spectroscopy. In the result of statistic analysis of these data we can make the following conclusions.

1. The discussed mineralogical methods of kimberlites diamondiferousness' evaluation indicate good similarity of results in the grade of diamonds for the pipes of one level. During evaluation of pipes which noticeably differ in diamondifeous property (pipes Udachnaya and Osennyaya, for instance) the indications start differing by an order. Those results are closer to actual values of diamondiferousness therewith which were achieved by calculation with application of absolute units (in $\mathrm{g} / \mathrm{t}$ ), but not of relative ones (per cent).

2. Maximum positive correlation was revealed between actual diamondiferousness and the quantity of garnets of diamond-pyrope deep-seated facies. Correlation factor noticeably decreases at comparison with general grade of garnets in a pipe and practically is absent at comparison with the quantity of ilmenite.

3. All mineralogical methods of diamondiferousness' evaluation, applied in comparison, were good at half-quantitative (more - less) level. And they are subordinated to nonlinear functional dependence. We used the procedures of ordinary regression for drawing up the latter one, which helped us to check up the hypothesis of its description by multiplicable and exponential models as the most close ones to the established dependence. The exponential dependence of diamond grade in kimberlite pipes from the quantity of garnets of diamond-pyrope deep-seated facies in them (see Fig.) was proved by the method of alignment (corresponding points lay on the straight line). Correlation coefficient between their logarithms is equal to +0.948 , that testifies about strong positive linear relationship between them. The method of linear regressive analysis was used to determine the equation illustrating the specified dependence. In the result the following equation was received:

$$
\mathrm{Di}=0.02844 \mathrm{e}^{0.02466 \mathrm{k}}
$$


where Di - productivity of a kimberlite body, car/t; k - grade of garnets of diamondpyrope deep-seated facies in it, g/t; e - basis of hyperbolic logarithm; 0.02844 and 0.02466 - constants.

Crushed samples with the weight of about $30 \mathrm{~kg}$ from several kimberlite bodies of Daldyn-Alakit region were selected to check up the suggested method. This provided the receipt of statistically representative selection of garnets with amount of not less than 250 grains from the concentrate of kimberlite heavy fraction. Paragenetically related with diamonds garnets were revealed in the selected garnets with the help of X-ray spectrum analysis or optical spectroscopy. Their percent with respect to the analyzed ones was determined, which then was multiplied by general quantity of garnets in a kimberlite body in $\mathrm{g} / \mathrm{t}$. By the established quantity of garnets of diamond-pyrope deep-seated facies, using the suggested equation, there was determined the productivity of a kimberlite body, that practically leads to easiest calculations or easiest data plotting. Comparison with actual kimberlite bodies' diamondiferousness therewith, received according to the data of exploitational exploration, indicates high similarity of results.

Thus, the suggested method of evaluation of kimberlite bodies' productivity allows for certain and exactly quantitatively determine their diamondiferousness according to the grade, in absolute units, of garnets of diamond-pyrope deep-seated facies in them.

\section{References}

1. Sobolev, N.V., 1974, Deep-seated inclusions in kimberlites and the problem of upper mantle composition: Novosibirsk, Science, p. 264.

2. Matsouk, S.S., Platonov, A.N., Khomenko, V.M., 1985, Optical spectrum and color of mantle minerals in kimberlites: Kiev, Naukova Dumka, p. 248.

3. Griffin, W.L., Ryan, C.G., Win, T.T., 1993, Trace elements in Garnets from the Udachnaya and Osennyaya Kimberlites: Application to Evaluation of Diamond Grade. SCIRO (Australia) Restricted Report 418R, North Ryde, p. 23. 


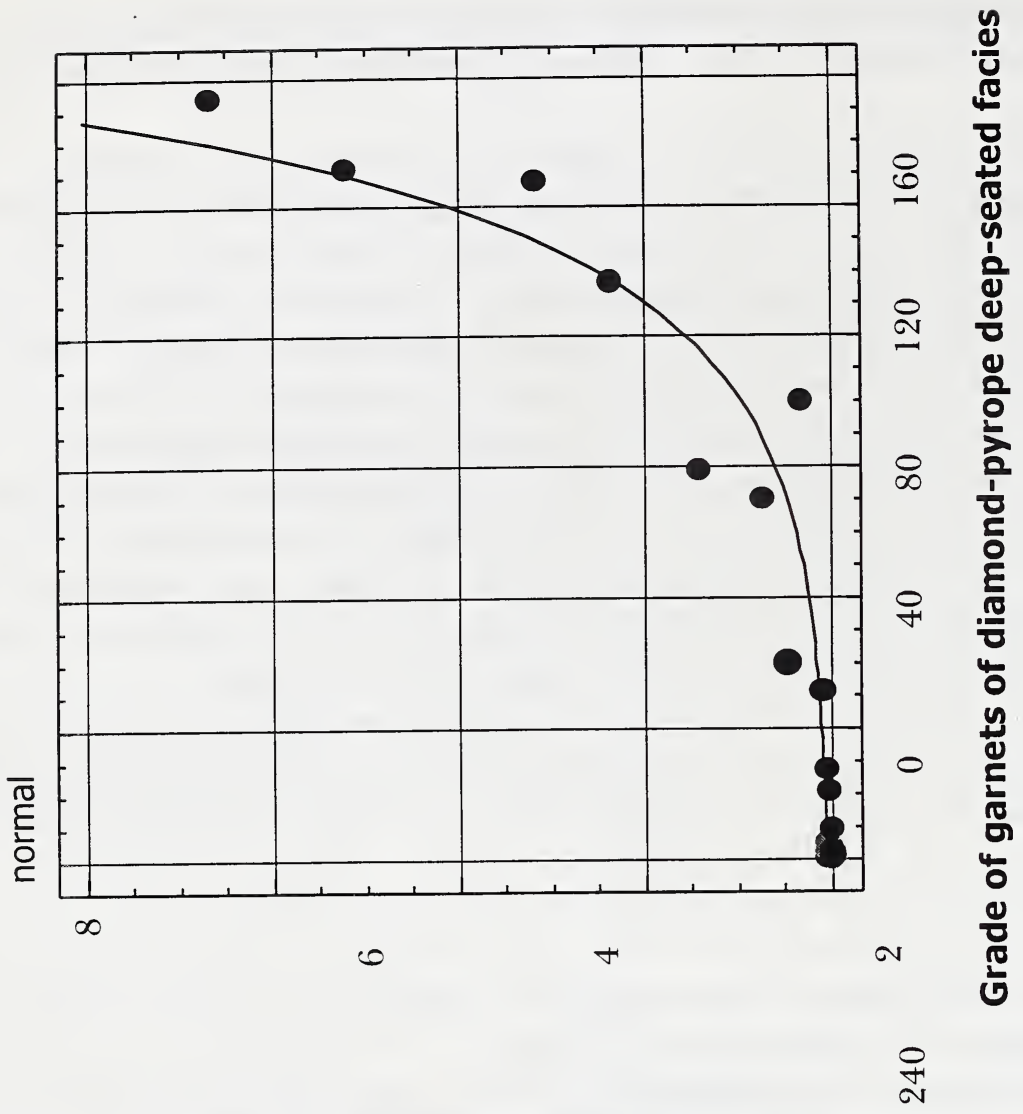

ż

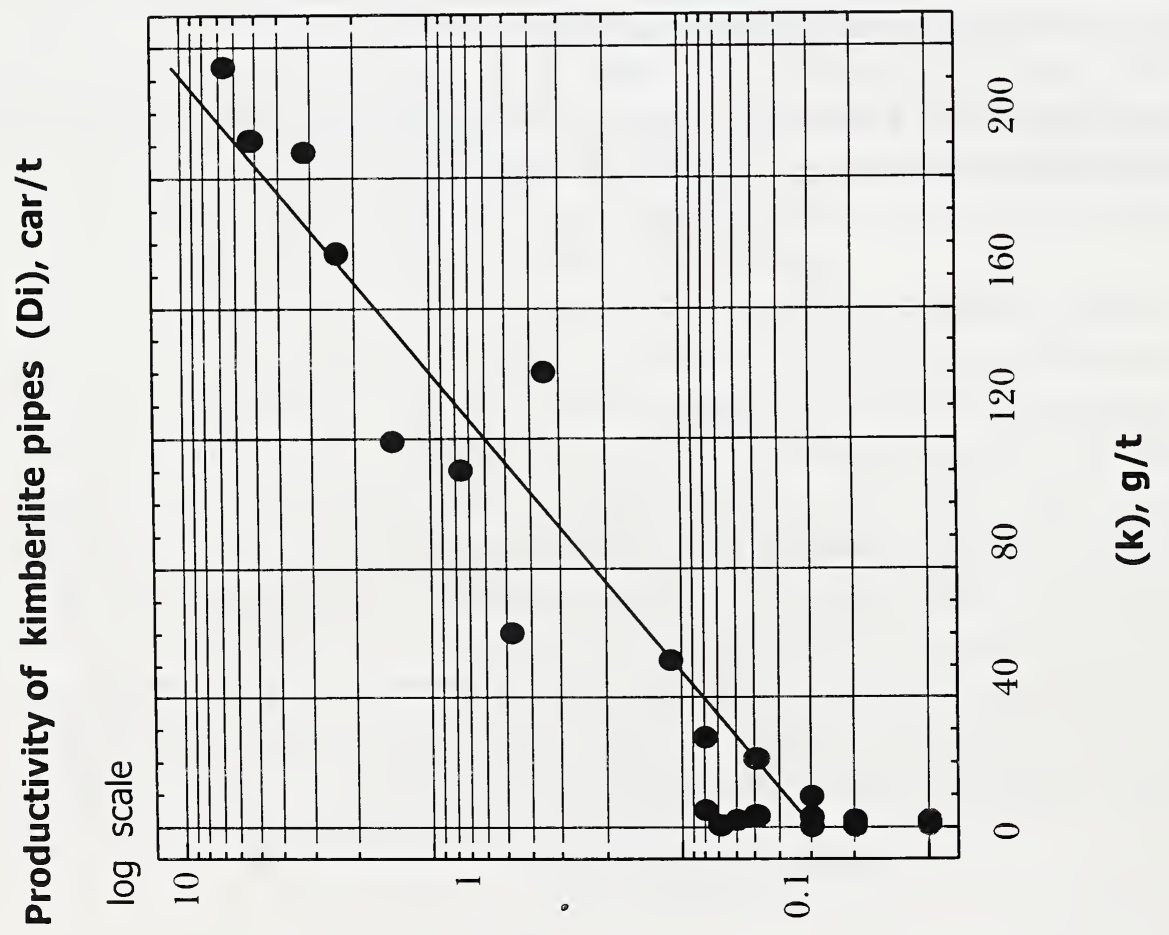

952 